\title{
APPLICATION OF PASSIVE-ACOUSTIC TELEMETRY TO EXPLORE THE BEHAVIOUR OF BALLAN WRASSE (Labrus bergylta) AND LUMPFISH (Cyclopterus lumpus) IN COMMERCIAL SCOTTISH SALMON SEA-PENS
}

Eric Leclercq ${ }^{1}$, Benjamin Zerafa, Adam J. Brooker, Andrew Davie and Hervé Migaud*

Institute of Aquaculture, University of Stirling, Stirling FK9 4LA, Scotland, UK.

Tel: +44 (0)1786 467886 / Fax: +44 (0)1768 472133

${ }^{1}$ Present Address: Lallemand Animal Nutrition, Blagnac, 31702, France.

*Corresponding author

E-mail: herve.migaud@stir.ac.uk

Telephone: +44 (0)1786 467886

Address: Institute of Aquaculture, University of Stirling, Stirling FK9 4LA, Scotland, UK.

Accepted refereed manuscript of: Leclercq E, Zerafa B, Brooker AJ, Davie A \& Migaud $\mathrm{H}$ (2018) Application of passive-acoustic telemetry to explore the behaviour of ballan wrasse (Labrus bergylta) and lumpfish (Cyclopterus lumpus) in commercial Scottish salmon sea-pens, Aquaculture, 495, pp. 1-12.

DOI: https://doi.org/10.1016/j.aquaculture.2018.05.024

(C) 2018, Elsevier. Licensed under the Creative Commons Attribution-NonCommercial-

NoDerivatives 4.0 International http://creativecommons.org/licenses/by-nc-nd/4.0/ 


\section{Abstract}

This study used passive-acoustic telemetry for the fine-scale, three-dimensional tracking of individual cleaner fish in commercial Scottish salmon sea-pens in full commercial operation. The aim was to test the system performance and provide baseline data on the comparative distribution and swimming activity of individual ballan wrasse and lumpfish under standard farm practices with the long-term aim of informing stocking and husbandry strategies. In March 2015, wild ballan wrasse (Labrus bergylta) $(115 \pm 20 \mathrm{~g} ; \mathrm{n}=13)$ and farmed lumpfish (Cyclopterus lumpus) $(281 \pm 42 \mathrm{~g} ; \mathrm{n}=13)$ previously deployed in June-October 2014 were recaptured, implanted with acoustic tags pinging every 6-12 sec and released into their original sea cage holding Atlantic salmon (Q2 2014; 2,059 \pm 35 g mean-weight). Control tags were deployed in cleaner fish hides to validate the system performance. Positional data from nine specimens per species were analysed from March $24^{\text {th }}$ to June $1^{\text {st }} 2015$, during which time water temperature rose from 7.2 to $9.1{ }^{\circ} \mathrm{C}$ and water salinity averaged $26.8 \pm 1.5$ ppt at $4 \mathrm{~m}$ depth. The accuracy of the acoustic positions averaged $0.6 \mathrm{~m}$ across the three dimensions of all control tags and was less than $1 \mathrm{~m}$ in $93 \%$ of all cases.

Significant differences in the distribution and activity of ballan wrasse and lumpfish were observed. Ballan wrasses spent $60 \pm 2 \%$ of the day-time at or below $15 \mathrm{~m}$, were positioned at significantly shallower depths at night and seldom used the hides provided despite an apparent resting behaviour at the pen bottom and corners. In comparison, lumpfish spent over $80 \%$ of the time above $10 \mathrm{~m}$, used hides extensively and preferentially at night $(50.1 \pm$ $2.1 \%$ at night), but to a lesser extent when the water temperature increased. The acoustic tracking system proved to be an effective tool for visualising cleaner fish behaviour under challenging farm conditions, and the study highlights the critical role of hides in cleaner fish husbandry. Overall, the study quantifies species-specific cleaner fish distribution in salmon 
net-pens supporting distinct interactions with the salmon stock and seasonal behaviour profiles. The results support the current commercial strategy of using two cleaner fish species against sea lice and the need for species-specific management strategies to optimise delousing activity.

Keywords: Acoustic telemetry, cleaner fish, ballan wrasse, lumpfish, behaviour, sea lice

\section{Highlights}

- Passive-acoustic telemetry is amenable to the study of the fine-scale behaviour of individual cleaner fish in commercial salmon net pens.

- Distinct, species-specific behaviours were observed in acoustic-tagged ballan wrasse and lumpfish.

- The study of individual cleaner fish behaviours using this technique will assist in optimising cleaner fish delousing efficiency under commercial conditions. 


\subsection{Introduction}

In recent years, cleaner fish have been implemented at a large scale in the North Atlantic salmon industry as a strategic component to the sustainable control of the potentially devastating salmon louse Lepeophtheirus salmonis (Boxaspen, 2006). This widespread and pivotal shift towards an integrated lice management relying heavily on biological control is unprecedented and unrivalled across intensively reared livestock. Although many challenges have been rapidly overcome to achieve the current level of biological delousing, the predictability and efficiency of this pest management strategy must be optimised across grow-out sites and through whole production cycles to ensure its long-term application and sector wide benefits. The implementation of effective biological delousing strategies must be informed by the requirements, behaviour and delousing activity of available cleaner fish species according to seasonal and local conditions and as a function of their origin and history.

The European industry is currently using wild-caught labrids, including ballan (Labrus bergylta), goldsinny (Ctenolabrus rupestris), corkwing (Crenilabrus melops), rockcook (Centolabrus exoletus) and cuckoo (Labrus mixtus) wrasse, in addition to farmed ballan wrasse and lumpfish (Cyclopterus lumpus) (Treasurer, 2013; Skiftesvik et al., 2014; Norwegian Directorate of Fisheries, 2015). However, the ambition is for total reliance on farmed specimens to secure sustainability and optimise biosecurity. Therefore, current efforts are increasingly focussed on the management of farmed ballan wrasse and lumpfish in cohabitation with salmon.

The ballan wrasse is a temperate species of the northeast Atlantic, with its range extending south to Morocco and north to Trondheim, Norway (Wheeler and Du Heaume, 1969; 
Quignard and Pras, 1986), and it is generally regarded as exhibiting diurnal behaviour, along with other European labrids (Costello, 1991; Turner and Warman; 1991; Darwall et al., 1992; Villegas-Rios, et al., 2013). They are nearshore-demersal fish being most abundant in shallow coastal rocky reefs and kelp beds at depths of 20-30 m (Dipper et al., 1977) and commonly shelter overnight in rock crevices (Costello, 1991). When deployed in salmon pens, therefore, shelters, or hides, should be provided for nocturnal resting and protection from predators, rough weather and during winter conditions. Recent delousing experiments and commercial results have suggested low swimming and foraging activity of ballan wrasse at temperatures below $9-10{ }^{\circ} \mathrm{C}$ (Treasurer, 2013; Lein et al., 2014) although high delousing was evident at $10.5^{\circ} \mathrm{C}$ in flow-through tanks (Leclercq et al., 2014).

Lumpfish are widely distributed across the North Atlantic, including Greenland. Juvenile and adult lumpfish generally live offshore exhibiting a semi-pelagic behaviour and are often associated with floating seaweed (Davenport, 1985; Ingólfsson and Kristjánsson, 2002 Kennedy et al., 2016). Adults switch between demersal habitats in the winter prior to their spring spawning migration when they exhibit large diel vertical migrations as they move towards shallow inshore waters where they often attach to rocky substrates (Davenport and Kjørsvik, 1986, Kennedy et al., 2016). The lumpfish is considered a suitable cold-water cleaner-fish species in salmon net-pens as it rapidly adapts to an open net-pen environment and exhibits a clear tendency to predate sea lice (Budney and Hall, 2010; Imsland et al., 2014a,b). It lacks a swim bladder but is almost neutrally buoyancy (Davenport and Kjorsvik 1986). An abdominal suction disc formed by a modified pelvic fin (Budney and Hall, 2010) facilitates its natural propensity for surface adhesion (Imsland et al., 2015), and it has a low aerobic scope (Killen et al., 2007). Ballan wrasse and lumpfish exhibit distinct life histories, biological features and habitat preferences; therefore, their sustainable use as biological 
agents within a non-dedicated farm environment requires the development of dedicated husbandry practices that preserve their health, welfare and survival throughout the salmon rearing cycle.

The key to the continual improvement of husbandry practices in any farming system is the observation of the livestock and the ability to rapidly identify deviations from normal behaviour and natural rhythms. However, the monitoring of cleaner fish deployed at low densities within commercial Atlantic salmon net-pens is difficult and remains largely anecdotal. Previous studies have either tried to extrapolate from tank studies (Leclercq et al. 2014, Imsland et al. 2016a) or used scuba diving observations and/or underwater video monitoring in experimental cage set-ups (Imsland et al., 2014b, 2016b) to provide valuable knowledge, but the scope of such work is constrained.

Passive-acoustic telemetry (as opposed to active acoustics where a transducer transmits sound pulses into the water and listens for echoes) uses underwater receivers (hydrophones) to listen for acoustic signals from aquatic animals fitted with acoustic transmitters, and is widely used in fisheries studies for survival studies and population monitoring (see Heupel et al., 2006; Kessel et al., 2014 \& Pollom et al., 2016 for reviews). Commonly, a fixed array of hydrophones is deployed across a known fish migration area (e.g. river or estuary) that records the movement of tagged fish through the array (e.g. Serrano et al., 2009; Roscoe et al., 2011) or a single mobile hydrophone setup is used to make transects of a study area and record the presence of tagged fish (e.g. Johnston et al., 2006). However, to the authors' knowledge, very few previous studies have used passive-acoustic telemetry in aquaculture net-pens (Rillahan et al., 2009, 2011; Føre et al., 2011), and this was in small experimental pens. Once fish are tagged and a hydrophone array is established, passive-acoustic telemetry 
can autonomously record fine-scale (sub-metre resolution), high temporal resolution (e.g. 1$60 \mathrm{sec}$ ), three-dimensional positions of multiple individuals over a period of weeks to months, depending on the battery life of the tags (Kessel et al., 2014). For this reason, such systems have already been successfully used to describe behaviour of wild adult ballan wrasse (Villegas-Rios et al. 2013) and lumpfish (Mitamura et al., 2012). For these reasons, the method is ideal for monitoring the fine-scale activity and behaviour of individual cleaner fish in salmon net pens in order to better understand the types of behaviours that relate to effective delousing. However, a commercial salmon farm is a challenging environment for acoustic telemetry due to regular underwater noise from farm operations, such as boat traffic, ADDs (Acoustic Deterrent Devices) and automated feeders, which may drown out acoustic tag signals, and underwater objects, such as the farm structure, nets and shoaling salmon, which may deflect or attenuate acoustic tag signals. Due to the significant influence of environmental and other factors on the performance and detection of acoustic receivers and the unique set of conditions found at every study site, it is important that these are carefully considered when designing a study system and that the system performance is tested thoroughly (Huveneers et al., 2016).

Therefore, the aims of this study were 1) to test the performance of a passive-acoustic telemetry system in an intensive net-pen aquaculture system under full commercial production, and 2) to generate preliminary baseline data on the comparative distribution and activity of the foremost cleaner fish species deployed within Atlantic salmon on-growing net-pens, ballan wrasse and lumpfish.

\subsection{Materials and Methods}

\subsection{Study site and animals}


The study was performed in a commercial salmon sea site $\left(56.69^{\circ} \mathrm{N}, 5.14^{\circ} \mathrm{W}\right.$, Loch Leven; Marine Harvest (Scotland) Ltd, UK) in two adjacent net-pens within a group of four floating square steel cages (HP 2000, Wavemaster, AKVA Group, Inverness, Scotland) each holding a double-sized net-pen $(24 \times 24 \mathrm{~m}$ square; 15 to $20 \mathrm{~m}$ depth inverted pyramid; $18 \mathrm{~mm}$ mesh) for in-situ biofouling control by switching the net bag and air-drying. At each pen corner, a ballast weight ( $1 \mathrm{t}$ concrete block) was suspended from the steel cage structure using a chain to $20 \mathrm{~m}$ depth onto which a slider weight was fitted to maintain the net tension.

At the start of the trial, experimental pens contained Q2 2014 Atlantic salmon ( $n=43,529 \pm$ $1,836$, body weight $=2,059 \pm 35 \mathrm{~g})$ and either wild labrids $(\mathrm{n}=3,200 ; 7.2 \%$ of salmon stock, pen 8) or farmed lumpfish $(\mathrm{n}=2,396 ; 5.7 \%$ of salmon stock, pen 7) previously deployed into these pens in June-July and October 2014, respectively. The wild labrid population included ballan $(57.9 \%, 78.2 \pm 5.8 \mathrm{~g}, 167 \pm 3 \mathrm{~mm}$ ), goldsinny (Ctenolabrus rupestris; 29.9 $\%$ ), corkwing (Crenilabrus melops, $7.6 \%$ ), rockcook (Centolabrus exoletus, $3.7 \%$ ) and cuckoo (Labrus mixtus, $0.9 \%)$.

Atlantic salmon were fed a commercial extruded diet (BioMar (UK) Ltd) to visual satiation twice daily using surface rotor spreaders and underwater video monitoring (Akvasmart CCS feed system, SmartEye 360 twin camera; AKVA Group). Two sinking wrasse hides (1 m Ø weighted ring; $2 \mathrm{~m}$ high; plastic fake-kelp (Leclercq et al., 2015)) were suspended from a rope within each pen at opposite corners at 8-12 m depth (Fig. 1), adjacent to which waterstable cleaner-fish feed blocks were presented weekly (600 g blocks, $\mathrm{n}=4$ / pen, Leclercq et al., 2015). Lumpfish received an additional five sinking hides (100 L plastic barrels suspended from the water surface; Fig. 1) at 4-5 m depth and were hand-fed a salmonid grower diet $(\varnothing 3 \mathrm{~mm})$ once daily to visual satiation at each hide, which had been briefly 
lifted. No therapeutic treatments against sea lice or other pathogens were administered during the study period. The mean sea lice count was obtained weekly on 10 salmon / pen and never exceeded 1.1 adults / salmon. Salmon and cleaner fish mortalities were removed daily using hand nets and an air-lift pump connected to a bottom collector (LiftUP Akva AS, Eikelandsosen, Norway); no significant mortality events occurred during the study. Water temperature, salinity and dissolved oxygen were measured at 30 min intervals at 1, 4, 8 and $12 \mathrm{~m}$ depth over the study duration (see supplementary data) using data loggers (HOBO U24-002C; HOBO U26-001; Onset Computer Corporation, Bourne, MA, USA) attached to a weighted line between both experimental pens and averaged $8.1 \pm 0.7^{\circ} \mathrm{C} ; 26.8 \pm 1.5 \mathrm{ppt}$; $11.8 \pm 0.8 \mathrm{mg} / \mathrm{L}$ at $4 \mathrm{~m}$ depth, respectively. All experiments were carried out in accordance with the Animal (Scientific Procedures) Act 1986 UK under the approval of the Institute of Aquaculture and University of Stirling ethical review boards.

\subsection{Acoustic telemetry system}

The three-dimensional acoustic tag tracking system (HTI-Vemco (USA) Inc., Seattle, WA, USA) used acoustic tags emitting at a single frequency $(307.2 \mathrm{kHz})$ but at a unique, userdefined pulse rate interval (PRI) to encode tag identification (Ehrenberg and Steig, 2009). The 3D positioning of each tag signal was achieved by measuring the time delay to at least four hydrophones deployed at known locations and in two planes. The study used an array of eight underwater hydrophones (Model 590 omni-directional) deployed surrounding both study net pens to ensure signal detection, with surface hydrophones $(n=4)$ suspended at 1 m depth below the cage walkway and bottom hydrophones $(n=4)$ attached to the ballast weights at $20 \mathrm{~m}$ depth (Fig. 1). The deployment of the hydrophones onto the pen structure itself permitted a constant positioning of the experimental pens relative to the hydrophone array, and hence, to the study coordinate system. This deployment strategy further allowed 
the routine manipulation of the net pens without affecting the hydrophone array. All the hydrophones were hardwired to an acoustic tag receiver (Model 290) housed on the cage structure, time synced via GPS satellite and with wireless connectivity to a shore-based personal computer for system control and raw data storage. Prior to the start of the trial, the position of each hydrophone relative to the others was determined by triangulation, or "pingaround", and preliminary testing identified the optimal settings for the specific conditions (data not shown), including tag signal $=1 \mathrm{msec}$ pulse-width, double-pulse non-encoded; hydrophone gain $=48 \mathrm{~dB}$; signal-to-noise ratio $=3$.

\subsection{Surgical procedure and tag deployment}

Each acoustic tag $(795 \mathrm{LD} ; 6.8 \times 20.0 \mathrm{~mm} ; 0.55 \mathrm{~g}$ in water) was programmed with a unique PRI ranging from 6,247 to $11,511 \mathrm{msec}$ and stored in a mild antiseptic solution $(0.5 \mathrm{~g} / \mathrm{L}$, Presept; Johnson \& Johnson, CA, USA) until implantation. Ballan wrasse or lumpfish were captured from the respective experimental pens using non-baited creel pots deployed at 6$12 \mathrm{~m}$ depth, slowly raised to the surface $(\sim 2 \mathrm{~m} / \mathrm{min})$, and the fish were isolated at sea (300 $\mathrm{L}$ perforated barrel) and starved for $48 \mathrm{~h}$ prior to surgery. Fish were individually anaesthetised (complete loss of reactivity) using Tricaine (80 ppm; 3-5 min; Pharmaq Ltd, Fordingbridge), examined for full external integrity, measured for body weight ( $\mathrm{BW} \pm 0.1$ g) and total body length (TL $\pm 1 \mathrm{~mm}$ ), prophylactically injected with antibiotic (oxytetracycline injected intramuscularly as Engemycin, $25 \mathrm{mg} / \mathrm{kg}$ ) and then transferred onto a wetted V-shaped bench for tag implantation. A small incision $(5-8 \mathrm{~mm})$ to the coelomic cavity was made antero-posteriorly, parallel and slightly off the ventral line anterior to the anal pore, using a fine scalpel. The tag was inserted postero-anteriorly with its emitter frontward. Two off-centred square knots sutures were made (Vicryl polyglactin 910, Ethicon), and an iodine-based antiseptic was applied locally prior to recovery in an aerated 
tank. The whole procedure did not exceed five minutes (as recommended by Marking and Meyer, 1985), during which frequent gill irrigation was provided using $60 \mathrm{ppm}$ tricaine and seawater alternately. All surfaces and surgical equipment were sanitised and chemically disinfected using sodium dichloroisocyanurate $(0.5 \mathrm{~g} / \mathrm{L}, 5 \mathrm{~min}$; Presept); surgical tools and tags were further rinsed in phosphate-buffered saline prior to use. Following recovery, fish were isolated at sea for $48 \mathrm{~h}$, then examined for survival and suture integrity prior to release in their original commercial net-pen.

Ballan wrasse and lumpfish were tagged on $3^{\text {rd }}(n=3 /$ species $)$ and $21^{\text {st }}(n=10 /$ species $)$ March 2015. Of the 13 wrasse tagged, three died prior to deployment, which were replaced by three new specimens released on $28^{\text {th }}$ March. Fish were surveyed from $24^{\text {th }}$ March to $1^{\text {st }}$ June $2015(\mathrm{n}=68$ days). In addition, control tags $(\mathrm{n}=5$; Model $795 \mathrm{LG} ; 11.0 \times 25.0 \mathrm{~mm})$ were programmed at 12,519-15,739 msec and deployed within cleaner-fish hides at known locations for testing the system performance over seven continuous days.

\subsection{Data processing and analysis}

Using a two-step procedure within the HTI software suite (MarkTags v6.10, AcousticTag v6.10, HTI-Vemco (USA) Inc., Seattle, WA, USA), raw acoustic data were transformed into positional data, consisting of a list of tag number and Coordinated Universal Time (UTC) stamp with three-dimensional Cartesian coordinates (x, y, z), within hourly databases. A noise filter was applied and individual tag signals identified based on their PRIs, following which a 3D algorithm was applied to calculate positional data for each individual tag pulse. The algorithm generated each position as the closest position to the centre of the cluster of positional solutions computed from four hydrophones with at least one from a distinct vertical plan with positions inferring a swimming speed above $2 \mathrm{~m} / \mathrm{sec}$ automatically 
discarded. Hourly positional databases were merged into daily files for further processing and coding using Microsoft Excel and Access ${ }^{\circledR}$ (Microsoft Office Professional Plus 2013) as follows: successive positional data were used to calculate the time between pulses, eliminate secondary pulses (sub-code periodicity $<2 \mathrm{sec}$ ) and calculate the minimum swimming speed (BL (body lengths) /sec) between successive positions based on cleaner fish body length at the time of tag implantation.

Based on their Cartesian coordinates, each recorded position was categorised into one of five locations within each pen: bottom (below $15 \mathrm{~m})$, pen corner $(6 \times 6 \mathrm{~m}, 0-15 \mathrm{~m}$ depth at each pen corner), edges (out with the theoretical pen volume or within $6 \mathrm{~m}$ along and inside the pen edges, corners excluded, $0-15 \mathrm{~m}$ depth $)$, centre $(13 \times 13 \mathrm{~m}$ centred at pen centre; $0-15$ m depth), or hides $(4 \times 4 \times 4 \mathrm{~m}$ centred to each shelter location as measured manually or using control tags). A degree of net-pen distortion from tidal flow occurred, and tidal flow also induced a pendulum movement of the cleaner fish hides, as evident from the spread of the positions of the control tags. The accuracy of the positioning of the control tags was, therefore, determined based on the median of all positions obtained over a seven-day period. Due to tidal distortion, the analysis of the cleaner fish distribution in the net-pen defined the hide area as a $4 \times 4 \times 4 \mathrm{~m}$ cube, despite being only $1 \mathrm{~m}$ wide and $2 \mathrm{~m}$ high, and pen edges up to $6 \mathrm{~m}$ inside the theoretical pen volume.

Based on their time stamp, each recorded position was coded for solar, tidal and salmon feeding status as follows: solar status (day, night) was based on sunrise and sunset times at Fort William, Scotland (http://www.timeanddate.com/sun/uk/fort-william) excluding $1 \mathrm{~h}$ prior to and after sunrise and sunset each day; tidal status was based on tidal charts from Loch Leven Head, Scotland (http://www.tidetimes.co.uk/loch-leven-head-tide-times) (high- 
and low-tide periods were defined as a 20 -min time period centred to each peak tide and, similarly, mid-tides (high flow) were defined as a 20-min time period centred between successive peak tides); salmon feeding periods (one morning and one afternoon meal daily) were recorded daily for each pen and computed excluding a 10-min transition period for comparison of cleaner fish positions during salmon feeding and day-time, non-feeding periods. Finally, to test the impact on cleaner fish behaviour of net biofouling, the three days immediately prior to and after each net change were coded and pooled across the experimental period (pen 7, lumpfish: 4 net swings, $\mathrm{n}=15$ days / biofouling status; pen 8 , ballan: 3 net swings, $\mathrm{n}=12$ days / biofouling status) for comparison.

Prior to analysis, the dataset was examined to eliminate data from fish believed to be dead or moribund based on their positions, i.e. showing a static profile at the pen bottom or water surface, following which the loss of tag signal usually occured within days due to mortality removal.

\subsection{Statistical analysis}

Linear regressions were performed using GraphPad Instat and conformed to a linear model with slopes significantly different to 0 . Significant differences in the mean of experimental groups were assessed by analysis of variance (ANOVA) manipulated by a general linear model using mean individual values per $24 \mathrm{~h}$ period. Prior to analyses, datasets were checked for normality using the Kolomogorov-Smirnov test and for homogeneity of variance using Levene's tests and observations of residual plots. Log or square-root transformations were applied when required to normalise the data and proportions were arc-sine transformed. Posthoc analyses were carried out using Tukey's Multiple Comparison tests. All statistical 
comparisons were performed using Minitab v.15 with a significance level of $5 \%(\mathrm{P}<0.05)$. Results are presented as mean \pm STDEV of individual and mean \pm SEM of population data.

\subsection{Results}

\subsection{System performance}

The theoretical number of signals emitted by control tags $(n=5)$ located in the wrasse hides were positioned in $92.5 \pm 1.7 \%$ of the cases, whereas $7.5 \pm 1.7 \%$ of the emitted pulses were not satisfactorily detected or positioned by the telemetry system (Table 1a). Similarly, when implanted in live ballan wrasse and lumpfish, positioning was achieved for $96.3 \pm 0.9$ and $92.7 \pm 1.6 \%$, respectively, of the total number of pulses emitted (data not shown). Across the five static tags and three dimensions ( $\mathrm{n}=15$ assessments), the absolute difference between the median of all acoustic positions (Table 1b) and the reference positions determined manually (Table 1c) averaged $0.58 \pm 0.15 ; 0.78 \pm 0.45 ; 0.44 \pm 0.47 \mathrm{~m}$ in the $\mathrm{x}-$, $y$ - and z-axis, respectively. The absolute discrepancy between the median of acoustic positions and the corresponding manual measurement was equal or below $0.5 \mathrm{~m}$ and $1.0 \mathrm{~m}$ in $53 \%$ and $93 \%$ of the cases, respectively.

Table 1: Control tags (a) location within cleaner fish hides and daily positioning rate; (b) estimated position by manual measurement and (c) by 3D telemetry positioning as determined over seven continuous days (days 96-103). Note: each shelter was subjected to pendular movements from tidal cycles that could not be measured manually.

\begin{tabular}{lccccc}
\hline \multicolumn{7}{l}{ a. Control tags location, periods and positioning rate } & & & \\
\hline Shelter number & $\mathbf{7 a}$ & $\mathbf{7 b}$ & $\mathbf{7 c}$ & $\mathbf{8 a}$ & $\mathbf{8 b}$ \\
Tag period (msec) & 15,739 & 12,519 & 14,507 & 15,235 & 13,527 \\
Total ping emitted (n) & 76,854 & 96,621 & 83,380 & 79,396 & 89,421 \\
Total ping positioned (n) & 72,066 & 91,243 & 78,145 & 68,085 & 84,606 \\
Daily positioning rate (\%) & $93.8 \pm 1.0$ & $94.4 \pm 1.4$ & $93.7 \pm 0.9$ & $85.8 \pm 1.2$ & $94.6 \pm 0.6$ \\
\hline
\end{tabular}




\begin{tabular}{|c|c|c|c|c|c|}
\hline \multicolumn{6}{|c|}{ b. Manual measurement (distance to origin, $\mathbf{m}$ ) } \\
\hline $\mathrm{x}$-axis & 13.0 & 29.5 & 24.5 & 55.0 & 40.0 \\
\hline$y$-axis & 34.5 & 15.0 & 35.5 & 34.5 & 14.5 \\
\hline z-axis & 8.5 & 10.5 & 5.0 & 9.0 & 11.0 \\
\hline \multicolumn{6}{|c|}{ c. Telemetry positioning: median (2nd - 98th percentile) (distance to origin, m) } \\
\hline $\mathrm{x}$-axis & $\begin{array}{c}13.5 \\
(11.5-15.3)\end{array}$ & $\begin{array}{c}29.1 \\
(26.4-31.3)\end{array}$ & $\begin{array}{c}25.0 \\
(23.7-26.3)\end{array}$ & $\begin{array}{c}54.3 \\
(51.6-56.9)\end{array}$ & $\begin{array}{c}39.2 \\
(37.2-41.4)\end{array}$ \\
\hline $\mathrm{y}$-axis & $\begin{array}{c}34.1 \\
(32.4-37.7)\end{array}$ & $\begin{array}{c}16.0 \\
(13.5-18.0)\end{array}$ & $\begin{array}{c}35.3 \\
(33.5-37.9)\end{array}$ & $\begin{array}{c}35.6 \\
(33.2-39.3)\end{array}$ & $\begin{array}{c}15.7 \\
(12.9-17.8)\end{array}$ \\
\hline z-axis & $\begin{array}{c}8.4 \\
(6.2-10.1)\end{array}$ & $\begin{array}{c}11.5 \\
(10.1-15.5)\end{array}$ & $\begin{array}{c}4.9 \\
(3.0-7.3)\end{array}$ & $\begin{array}{c}8.1 \\
(6.3-9.6)\end{array}$ & $\begin{array}{c}10.9 \\
(9.3-17.2)\end{array}$ \\
\hline
\end{tabular}

\subsection{Fish survival and loss of tag signal}

From a total of 13 ballan wrasse and 13 lumpfish tagged and released $48 \mathrm{~h}$ post-surgery, four specimens per species were discarded from the survey due to signal loss within 20 days of deployment. Consequently, a total of nine specimens / species were surveyed (Fig. 2; Table 2) among which five ballan wrasse and four lumpfish were detected throughout the experimental period. In the other tagged specimens, loss of tag signal was preceded by one to several days of behavioural data indicating a probable moribund or dead state, i.e. a relatively static location at the pen bottom, and these positional data were discarded prior to analysis.

Table 2: (a) Body-size parameters of experimental cleaner fish (Mean $\pm \mathrm{SE}$ )

\begin{tabular}{lccc}
\hline & & Wrasse & Lumpfish \\
\hline Quantity & $(\mathrm{n})$ & 9 & 9 \\
Body-weight & $(\mathrm{g})$ & $115 \pm 20$ & $281 \pm 42$ \\
Length & $(\mathrm{mm})$ & $192 \pm 12$ & $178 \pm 9$ \\
Fulton's condition factor & & $1.47 \pm 0.02$ & $4.59 \pm 0.26$ \\
Tag-weight (in water) to body-weight ratio & $(\%)$ & $0.65 \pm 0.14$ & $0.26 \pm 0.1$ \\
\hline
\end{tabular}

\subsection{Depth and swimming activity}

Positional data collected over a 48 h period from individual ballan wrasse (Tag 8907; Fig.

3) and lumpfish (Tag 10503; Fig. 4) are presented for illustration. Ballan wrasse 8907 
covered a relatively low proportion of the pen volume and exhibited a clear diurnal pattern being positioned at the pen bottom during the day (20-22 $\mathrm{m}$ depth) and swimming up to 5 $\mathrm{m}$ along two distinct pen corners during the night (Fig. 3). In comparison, lumpfish 10503 showed a less sedentary behaviour covering a higher proportion of the pen volume (Fig. 4). It did not show a diurnal pattern in its depth profile, but instead spent most of the $48 \mathrm{~h}$ period at 5-10 $\mathrm{m}$ depth with frequent, short and visits to deeper depths.

Over the study period, three wrasse specimens (33.3\%) and one lumpfish (11\%) showed a significant diurnal pattern in depth, being significantly deeper during daytime than during night time (Fig. 5a). At the population level, wrasse were significantly deeper during the day than during the night, and lumpfish were always significantly shallower than wrasse with no differences in depth between daytime and night time (Table 3). Accordingly, lumpfish spent significantly more time than wrasse above $10 \mathrm{~m}$ depth $(81.3 \pm 1.6$ and $82.2 \pm 1.8 \%$ for lumpfish compared to $14.9 \pm 0.8$ and $29.6 \pm 1.2 \%$ for wrasse during daytime and night time, respectively) (Table 3). Over the study period, the mean daily depth of ballan wrasse significantly decreased during daytime $\left(\mathrm{r}^{2}=0.408 ; \mathrm{P}<0.001\right)$ and night time $\left(\mathrm{r}^{2}=0.790 ; \mathrm{P}\right.$ $<0.001$; Fig. 5b) and was inversely correlated with ambient water temperature (daytime $\mathrm{r}^{2}$ $=0.584 ; \mathrm{P}<0.0001$; night time: $\mathrm{r}^{2}=0.173 ; \mathrm{P}<0.001$; supplementary data). In comparison, the mean daily depth of lumpfish did not vary over time (Fig. 5c), and hence, was not correlated with ambient water temperature (daytime $\mathrm{r}^{2}=0.030 ; \mathrm{P}=0.157$; night time $\mathrm{r}^{2}=$ 0.002; $\mathrm{P}=0.705)$. No diurnal pattern in minimum swimming speed was observed at the individual (Fig. 6a) nor at the population level (Table 3) for both species. Mean daily swimming speed (relative to body length) was significantly higher for lumpfish than for ballan wrasse during both daytime and night time (Table 3). The mean daytime and night time swimming speeds of wrasse significantly decreased over the study period $\left(r^{2}=0.408\right.$ 
and 0.559 , respectively, $\mathrm{P}<0.001$ ) (Fig. 6b), while for lumpfish, night time swimming speed significantly decreased and daytime swimming speed significantly increased over the study period (Fig. 6c) $\left(\mathrm{r}^{2}=0.326 ; \mathrm{P}<0.001\right)$.

Table 3: Effects of sunlight on the swimming activity, depth and distribution of ballan wrasse and lumpfish populations in salmon net pens over 69 days. Data are expressed as mean \pm SE where $n=5-9$ ballan wrasse and 4-9 lumpfish. Superscript letters represent significance groups with different letters denoting significant differences from other groups.

\begin{tabular}{lcccc}
\hline & \multicolumn{2}{c}{ Ballan wrasse } & \multicolumn{2}{c}{ Lumpfish } \\
\hline Day/night & Day & Night & Day & Night \\
Swim. speed (BL/sec) & $0.20 \pm 0.00^{\mathrm{b}}$ & $0.20 \pm 0.00^{\mathrm{b}}$ & $0.29 \pm 0.00^{\mathrm{a}}$ & $0.28 \pm 0.01^{\mathrm{a}}$ \\
Depth (m) & $16.3 \pm 0.2^{\mathrm{a}}$ & $13.8 \pm 0.2^{\mathrm{b}}$ & $7.1 \pm 0.2^{\mathrm{c}}$ & $6.5 \pm 0.2^{\mathrm{c}}$ \\
Average proportion of time spent at different depth layer (\%) & & \\
$<5 \mathrm{~m}$ & $3.2 \pm 0.6^{\mathrm{c}}$ & $9.9 \pm 1.1^{\mathrm{c}}$ & $39.6 \pm 1.6^{\mathrm{b}}$ & $47.0 \pm 1.8^{\mathrm{a}}$ \\
5 to $9.9 \mathrm{~m}$ & $11.7 \pm 1.1^{\mathrm{c}}$ & $19.7 \pm 1.4^{\mathrm{b}}$ & $41.7 \pm 1.6^{\mathrm{a}}$ & $35.2 \pm 1.8^{\mathrm{a}}$ \\
10 to $14.9 \mathrm{~m}$ & $25.4 \pm 1.3^{\mathrm{a}}$ & $29.3 \pm 1.1^{\mathrm{a}}$ & $12.3 \pm 0.9^{\mathrm{b}}$ & $11.0 \pm 0.9^{\mathrm{b}}$ \\
$\geq 15 \mathrm{~m}$ & $59.7 \pm 1.5^{\mathrm{a}}$ & $41.1 \pm 1.6^{\mathrm{b}}$ & $6.4 \pm 0.9^{\mathrm{c}}$ & $6.8 \pm 0.9^{\mathrm{c}}$ \\
Average proportion of time spent at different pen location & $(\%)$ & \\
Edges & $11.5 \pm 0.6^{\mathrm{c}}$ & $20.0 \pm 0.7^{\mathrm{b}}$ & $28.5 \pm 0.9^{\mathrm{a}}$ & $23.6 \pm 0.8^{\mathrm{ab}}$ \\
Corners & $21.7 \pm 0.1^{\mathrm{b}}$ & $30.0 \pm 1.0^{\mathrm{a}}$ & $27.5 \pm 1.4^{\mathrm{ab}}$ & $19.1 \pm 1.2^{\mathrm{b}}$ \\
Centre & $0.7 \pm 0.0^{\mathrm{b}}$ & $0.5 \pm 0.2^{\mathrm{b}}$ & $3.5 \pm 0.4$ & $1.5 \pm 0.2^{\mathrm{a}}$ \\
Shelters & $6.3 \pm 0.1^{\mathrm{c}}$ & $8.2 \pm 0.7^{\mathrm{c}}$ & $35.2 \pm 2.0^{\mathrm{b}}$ & $50.1 \pm 2.1^{\mathrm{a}}$ \\
Pen bottom $(\geq 15 \mathrm{~m})$ & $59.8 \pm 1.5^{\mathrm{a}}$ & $41.3 \pm 1.5^{\mathrm{b}}$ & $5.3 \pm 0.8^{\mathrm{c}}$ & $5.7 \pm 0.8^{\mathrm{c}}$ \\
\hline
\end{tabular}

\subsection{Pen habitat usage}

The profile of pen habitat usage over time is presented per species during both daytime and night time (Fig. 7) and summarised over the study period (Table 3). Lumpfish spent significantly more time in the hides during the night $(50.1 \pm 2.1 \%)$ than during the day $(35.2$ $\pm 2.0 \%)$ and otherwise preferred the pen edges and corners with no significant diurnal variations. In comparison, ballan wrasse seldom used the hides during the day or night; they were present at the pen edges and corners significantly more during the night $(50.0 \pm 0.8 \%)$ 
than during the day $(33.2 \pm 0.3 \%)$ and were otherwise located below $15 \mathrm{~m}$, i.e. at the pen bottom.

\subsection{Effect of key environmental parameters and management practices}

Tide and water flow had no apparent effect on the swimming speed, depth and habitat distribution of both species, except that wrasse exhibited a significantly higher swimming speed at low tide compared to high tide. Behavioural parameters did not significantly vary prior to net changes compared to after net changes for biofouling control, or during feeding compared to non-feeding of the salmon stock.

\subsection{Discussion}

The telemetry system used in this study combined a high position-detection rate with submetre accuracy, thereby generating reliable, high-frequency 3D positional data of individual cleaner fish deployed within a salmon sea farm site. Positional data were acquired continuously over a 2-month period without affecting commercial operations allowing the comparative assessment of ballan wrasse and lumpfish distribution according to prevalent environmental and commercial farm conditions. Ballan wrasse and lumpfish at low stocking densities in salmon net-pens exhibited strong individual variability, but species-specific patterns in depth distribution, swimming speed and pen habitat usage were apparent.

\subsection{System performance and limitations}

The system used was designed to optimise detection range in freshwater (up to $1 \mathrm{~km}$ ) by using a $307 \mathrm{kHz}$ signal frequency. However, high detection rates were achieved in the current study in seawater due to the relatively small pen volume area $(24 \times 24 \times 15-20 \mathrm{~m})$ and surrounding hydrophone array (42 $\mathrm{m}$ diagonal separation), as previously reported in Atlantic 
cod within net-pens of similar sizes (Rillahan et al., 2009). The commercial number and theoretical minimum salmon density in this study $\left(12-15 \mathrm{~kg} / \mathrm{m}^{3}\right)$ did not significantly impact tag signal transmission. The deployment of the hydrophone array outside the net-pens was, therefore, effective but also practical. First, it did not interfere with normal commercial operations, including net-changes, without disturbing the hydrophone array and causing subsequent positioning error. Second, by using the floating steel frame and ballast as anchor points for the hydrophones, positions were automatically generated relative to the net-pens regardless of vertical and horizontal drift due to tidal flows. Critically, the acoustic deterrent device (ADD; Program 4; DSMS-4 Terecos Ltd, Glasgow, Scotland, UK) used at the site for deterring predators did not compromise tag detection or positioning despite generating high-intensity sound of varying frequencies. The ADD produces broadband signals between 2 and $40 \mathrm{kHz}$ with additional signal components beyond this range (Harris et al., 2014; Lepper et al., 2004). The ADD signal was effectively filtered out during the data acquisition stage, as was the sound emitted by the farm workboats, which typically ranged from 20 to $200 \mathrm{kHz}$ (Tyack, 2008). Using a telemetry system that optimises tag detection range in seawater (e.g. $80 \mathrm{kHz}$; marine acoustic tag range, HTI-Vemco (USA) Inc.) does not, therefore, appear to be necessary for fine-scale tracking in marine net-pen aquaculture systems, although it may allow fewer hydrophones to be used when tracking within a group of pens. However, the detection of these lower tag frequencies within a noisy farm environment may be problematic due to the tag frequency being within the range of the farm noise. Huveneers et al. (2016) showed that receiver depth and orientation and time since deployment had the largest effect on detection performance, while wind direction, precipitation and atmospheric pressure had little or no effect. However, the shallow depth of the study site and relatively short deployment in the current study meant that these factors did not noticeably affect performance. 
A total of 31 active tags were deployed at the start of the trial. Although only nine specimens per species and five control tags were ultimately analysed, no further tags were deployed to avoid overloading the system. Unlike wild telemetry studies (e.g. salmonid migration) where tagged fish pass only briefly through a hydrophone array, each tag was continuously received by the hydrophone array. Furthermore, the tags had a high PRI (6-12 sec) and used a double pulse signal to facilitate tracking in a noisy environment, generating a large volume of primary data $(\sim 700,000$ observations daily). However, the system successfully processed incoming data during the study, and it is estimated that 40 tags could be tracked simultaneously using this setup. More tags may be deployed if the PRI and/or number of hydrophones were reduced to decrease data volume, although the volume of acoustic data generated within an enclosed system is a key limitation, requiring a high computational processing power.

Given its performance in an intensive net-pen aquaculture system and the capability of realtime positioning, this technology could be used for sentinel observation of behaviour as an indicator of foraging activity, health and welfare in aquaculture species (Martins et al., 2012). Furthermore, sensor technology has evolved rapidly in recent years, and incorporating this into acoustic tags may allow real-time monitoring of physiological data, such as ventilation rate, muscular activity and heart rate to enhance the value of such sentinel-based observations. In Atlantic salmon stocks, tagged sentinel fish would provide an early identification of disease, stress or environmental stressors known to alter behaviour (Martins et al., 2012). 
A total of 13 cleaner fish / species were tagged in this study, among which four specimens per species were discarded due to signal loss within 20 days. The origin of signal loss could not be identified but could be due to independent factors (e.g. predation), the surgery and tag implantation procedure (e.g. tag loss) or tag failure. To mitigate these factors as much as possible, the tagging surgery was carried out by trained scientists and fish veterinary surgeons with detailed handling, equipment and sanitary protocols and prophylactic treatments based on recommendations by Mulcahy, 2003 .

A further concern is the possible alteration of behaviour due to the tagging procedure and/or the implanted tag. However, the weight of the tag relative to the body weight of each specimen never exceeded $2 \%$ and $1 \%$ the weight of the tag in air and water, respectively as recommended by Winter (1996). Indeed, Brown et al. (1999) and Perry et al. (2001) observed no adverse effects in salmonids fitted with tags weighing up to $12 \%$ and $9.5 \%$ of the fish body weight, respectively. In other studies, surgical implantation appeared to have little effect on survival, growth or behaviour of salmonids (Adams et al., 1998) or Atlantic cod (Wroblewski et al., 1994; Cote et al., 1999). Furthermore, a body of previous work has found no evidence to suggest changes in buoyancy, orientation, swimming, feeding, haematological response, predation or gonad development in a range of species implanted with acoustic tags (Bridger \& Booth, 2003).

\subsection{Ballan wrasse and lumpfish behaviour}

In this study, ballan wrasse spent $60 \%$ of the daytime at $15 \mathrm{~m}$ or below, i.e. within the inverted pyramid down to $20 \mathrm{~m}$ depth, and were repeatedly observed resting at the pen bottom on the farm underwater video cameras used for monitoring the salmon stocks. This is in accordance with a previously published report (Treasurer, 2013) and in line with the 
demersal behaviour of the species (Dipper et al., 1977; Figueiredo et al., 2005). However, more than $15 \%$ of the positions during the daytime were above $10 \mathrm{~m}$ depth, and characteristic feeding marks were observed on the feed blocks presented at $\sim 10 \mathrm{~m}$ depth. Feed intake was weak (estimated at 0.1 to $0.5 \%$ biomass / day, data not shown) and could not be accurately quantified, but confirms that, despite spending most of their time at the bottom of the pen, wrasse still displayed behaviour that may be interpreted as foraging activity. This suggests a potential for delousing at temperatures below $10{ }^{\circ} \mathrm{C}$ (wrasse were previously thought to be ineffective delousers in Scottish winter temperatures (Treasurer, $2002,2013))$. The mean depth of the wrasse during the daytime decreased from $18 \mathrm{~m}$ to 14 m during the study, which coincided with the spring rise in water temperature from 7.2 to $9.1{ }^{\circ} \mathrm{C}$ and confirms the effect of water temperature on vertical distribution as observed for biological delousing (Treasurer, 2013). Interestingly, a third of the specimens preferred shallower depths at the pen corners during night time in a consistent diurnal pattern. Night time migration to the pen corners was unlikely to be related to foraging (Turner and Warman; 1991) but may have been driven by nocturnal sheltering (Costello, 1991), particularly considering that pen corners provide proximity to two vertical net surfaces. The hides were nonetheless seldom used by the tagged ballan wrasse despite a nine-month acclimation period in the rearing system prior to the experiment. This may imply that the hides failed to attract the wrasse due to an inappropriate design or location within the pen or that the hides were occupied by untagged wrasse and the study fish were excluded through some form of unknown hierarchy. Wrasse hides are considered essential for wrasse maintenance in salmon net-pens and should provide resting areas to reduce predation risk (Treasurer, 2013). Behavioural data reported in this study suggest that hides should be located near the pen corners and the pen bottom while taller hides may help encourage wrasse to use shallower depths. The apparent nocturnal behaviour described indicates that creel pots for wrasse re- 
capture, particularly if un-baited for random sampling, should be placed at the pen corners, deployed overnight during shelter seeking and could be deployed at shallower depths in an attempt to minimise swim bladder over-inflation from rapid decompression in this physoclistous species (Helfman et al., 2009).

In contrast to ballan wrasse, lumpfish spent the majority of their time in the top $10 \mathrm{~m}$ of the pen in line with their natural epipelagic behaviour (Davenport and Kjørsvik, 1986). They did not show a diurnal pattern in vertical distribution and spent over a third of the daytime and half of the night time in the hides. Hides were, therefore, well accepted, confirming the suitability of smooth vertical plastic surfaces for lumpfish (Imsland et al.; 2015), and they were preferentially but not only used during night time. In addition, the use of the hides decreased as the water temperature increased concomitant with increased swimming speeds, suggesting an increasing foraging activity over the spring period. In comparison, lumpfish stocked in net-pens without hides were documented to rest only $8 \%$ of the daytime but to actively feed and swim for $65 \%$ and $25 \%$ of the daytime, respectively (Imsland et al., 2014b). Lumpfish were also previously found to have a very limited aerobic scope, and juveniles preferentially use the 'cling-foraging strategy', despite being capable of both active and ambush search strategies (Killen et al., 2007). Together, these data indicate that lumpfish hides have a critical role to play in their maintenance, as may be expected from the species' abdominal sucker. Nonetheless, lumpfish are active swimmers, and they perform long migrations away from coastal spawning areas against the prevailing currents (Mitamura et al. 2012). The swimming speed of lumpfish (relative to body size) was indeed $30 \%$ higher overall than that of ballan wrasse suggesting a higher activity at the water temperatures experienced during the study. Future studies should investigate the effect of selectively removing hides to encourage active foraging during periods of excessive sea lice burden. 
Compared to the wrasse, the lumpfish in this study were more active on the vertical scale, i.e. they changed depth more often, while cruising across all four sides of the net. Such rapid vertical migration patterns are likely facilitated by the near neutral buoyancy of the species achieved, in the absence of a swim bladder, from their cartilaginous skeleton, extensive subcutaneous jelly concentrated in the dorsal hump and loose-fibred dorsal muscles (Davenport and Kjørsvik, 1986). The reasons for these rapid changes in depth are unknown, but it may simply be that lumpfish are not constrained by the limitations of a swim bladder and are able to move vertically as quickly and easily as moving horizontally in the water.

In addition to the effects of temperature and the diurnal photoperiod cycle, the effect of the tidal cycle was assessed, but with no apparent effect on the distribution and swimming activity of either cleaner fish species. However, the cage site used is considered a sheltered site with medium water flow (mean flow $5.9 \mathrm{~cm} / \mathrm{sec}$ over 15 days and across the entire depth of the water column; Nielsen, 2011). Further studies should be performed in high-energy sites, ideally using on-site current meters, as nearby tidal stations may not truly reflect local tidal conditions throughout entire loch systems. The impact on cleaner fish behaviour of two commercial practices was assessed, salmon feeding and net-changes for biofouling control, and neither had any significant impact on the depth distribution, activity or habitat use of ballan wrasse or lumpfish.

\subsection{Conclusions}

A passive-acoustic telemetry system was tested for the first time in an aquaculture net-pen system under full commercial operation. It performed very well under the challenging farm conditions, including high salmon densities, tidal flows and salinity variations, as well as anthropogenic noise. It proved to be an effective tool for visualising cleaner fish distribution 
and swimming activity in commercial salmon net-pens. As expected from their different ecology and morphology, the study identified several differences between ballan wrasse and lumpfish behaviour. Ballan wrasse exhibited a high residency at the pen bottom and corners, while lumpfish covered a greater pen volume despite significant use of the hides over the low-temperature spring study period. This provides evidence to support the currently anecdotal seasonal profile of delousing activity in both species and suggests distinct interactions of each species with the salmon biomass. These different behaviours may support a strategy using two cleaner fish species to optimise delousing although further studies are required to investigate delousing efficiency under these conditions and how the two species might interact. The study highlights the need to improve ballan wrasse hide deployment strategy and the possibility of using lumpfish hides to control their distribution and activity. This type of tracking technology will permit the comparison of the seasonal activity of different cleaner fish species and origins, e.g. farmed and wild, in order to inform best stocking strategies and husbandry practices. Such future work is required to improve the predictability of biological delousing and the overall welfare of cleaner fish populations in salmon sea sites.

\section{Acknowledgements}

The authors would like to thank staff at the Loch Leven (Ballachulish) sea site and HTIVemco (USA) Inc. for their technical support.

\section{Source of funding}

This project was funded by a 2013/2014 Sainsbury's Agriculture R\&D Grant, the Scottish Aquaculture Innovation Centre and Marine Harvest (Scotland) Ltd. The funders did not contribute to the study design or collection, analysis and interpretation of data. 


\section{Author contributions}

The study was designed by HM, EL \& AD, executed by EL and HM with data analysed by EL, BZ and AB, All authors contributed to the writing of, have seen and approved the final manuscript. 


\section{References}

Adams, N.S., Rondorf, D.W., Evans, S.D., Kelly, J.E., 1998. Effects of surgically and gastrically implanted radio transmitters on growth and feeding behavior of juvenile Chinook salmon. Trans. Am. Fish. Soc. 127, 128-136.

Bridger, C.J., Booth, R.K., 2003. The Effects of Biotelemetry Transmitter Presence and Attachment Procedures on Fish Physiology and Behavior. Rev. Fish. Sci. 11, 13-34.

Boxaspen, K., 2006. A review of the biology and genetics of sea lice. ICES J. Mar. Sci. 63, $1304-1316$.

Brown, R.S., Cooke, S.J., Anderson, W.G., McKinley, R.S., 1999. Evidence to challenge the "2\% rule" for biotelemetry. N. Am. J. Fish. Manage. 19, 867-871.

Budney L., Hall B., 2010. Comparative morphology and osteology of pelvic fin-derived midline suckers in lumpfishes, snailfishes and gobies. J. Appl. Ichthyol. 26, 167-175.

Costello, M.J., 1991. Review of the biology of wrasse (Labridae: Pisces) in Northern Europe. Prog. Underwat. Sci. 16, 29-51.1

Cote, D., Scruton, D.A., Cole, L., McKinley, R.S., 1999. Swimming performance and growth rates of juvenile Atlantic cod intraperitoneally implanted with dummy acoustic transmitters. N. Am. J. Fish. Manage. 19, 1137-1141. 
Darwall, W., Costello, M., Donnelly, R., Lysaght, S., 1992. Implications of life-history strategies for a new wrasse fishery. J. Fish. Biol. 41, 111-123.

Davenport, J., 1985. Synopsis of biological data on the lumpsucker, Cyclopterus lumpus (Linnaeus, 1758). FAO Fish. Synop. 7, 6-7.

Davenport J, Kjørsvik, E., 1986. Buoyancy in the lumpsucker Cyclopterus lumpus. J Mar Biol Assoc. 66, 159-174.

Dipper, F., Bridges, C., Menz, A., 1977. Age, growth and feeding in the ballan wrasse Labrus bergylta Ascanius 1767. J. Fish. Biol. 11, 105-120.

Ehrenberg, J.E., Steig, T.W., 2009. A study of the relationship between tag-signal characteristics and achievable performances in acoustic fish-tag studies. ICES J. Mar. Sci. $66,1278-1283$.

Figueiredo, M., Morato, T., Barreiros, J.P., Afonso, P., Santos, R.S., 2005. Feeding ecology of the white seabream, Diplodus sargus, and the ballan wrasse, Labrus bergylta, in the Azores. Fish. Res. 75, 107-119.

Føre, M., Alfredsen, J.A. and Gronningsater, A., 2011. Development of two telemetry-based systems for monitoring the feeding behaviour of Atlantic salmon (Salmo salar L.) in aquaculture sea-cages. Comp. Elec. Agric. 76, 240-251. 
Harris, R., Harris, C., Duck, C., Boyd, I., 2014. The effectiveness of a seal scarer at a wild salmon net fishery. ICES J. Mar. Sci. 71, 1913-1920.

Helfman, G., Collette, B.B., Facey, D.E., Bowen, B.W., 2009. A history of fishes. In: Andrew, J., Clarke, A., Hall, D., Vives, S., Reynolds, C., Motta, P. (Eds.), The diversity of fishes: biology, evolution, and ecology ( $2^{\text {nd }}$ edition). Wiley-Blackwell, Hoboken, New Jersey, pp. 195-197.

Heupel, M.R., Semmens, J.M., Hobday, A.J., 2006. Automated acoustic tracking of aquatic animals: Scales, design and deployment of listening station arrays. Mar. Fresh. Res. 57, 113.

Huveneers, C., Simpfendorfer, C.A., Kim, S., Semmens, J.M., Hobday, A.J., Pederson, H., Stieglitz, T., Vallee, R., Webber, D., Heupel, M.R., Peddemors, V., Harcourt, R.G., 2016. The influence of environmental parameters on the performance and detection range of acoustic receivers. Methods Ecol. Evol. 7, 825-835.

Imsland, A.K., Reynolds, P., Eliassen, G., Hangstad, T.A., Foss, A., Vikingstad, E., Elvegård, T.A., 2014a. The use of lumpfish (Cyclopterus lumpus L.) to control sea lice (Lepeophtheirus salmonis Krøyer) infestations in intensively farmed Atlantic salmon (Salmo salar L.). Aquac. 424-425, 18-23.

Imsland, A.K., Reynolds, P., Eliassen, G., Hangstad, T.A., Foss, A., Vikingstad, E., Elvegård T.A., 2014b. Notes on behaviour of lumpfish with and without Atlantic salmon present. J Eth. 32, 117-122. 
Imsland, A.K., Reynolds, P., Eliassen, G., Hangstad, T.A., Nytrø, A.V., Foss, A., Vikingstad, E., Elvegård, T.A., 2015 Assessment of suitable substrates for lumpfish in sea pens. Aquac. Int. 23, 639-645.

Imsland, A.K., Reynolds, P., Eliassen, G., Hangstad, T.A., Jónsdóttir, Ó.D., Elvegård, T.A., Lemmens, S.C., Rydland, R. and Nytrø, A.V., 2016a. Investigation of behavioural interactions between lumpfish (Cyclopterus lumpus) and goldsinny wrasse (Ctenolabrus rupestris) under controlled conditions. Aquaculture International, 24(5), pp.1509-1521.

Imsland, A.K., Reynolds, P., Nytrø, A.V., Eliassen, G., Hangstad, T.A., Jónsdóttir, Ó.D., Emaus, P.A., Elvegård, T.A., Lemmens, S.C., Rydland, R. and Jonassen, T.M., 2016b. Effects of lumpfish size on foraging behaviour and co-existence with sea lice infected Atlantic salmon in sea cages. Aquaculture, 465, pp.19-27.

Ingólfsson, A., Kristjánsson, B.K., Schaefer, S., 2002. Diet of juvenile lumpsucker Cyclopterus lumpus (Cyclopteridae) in floating seaweed: effects of ontogeny and prey availability. Copeia. 2, 472-476.

Johnston, S.V., Rivera, J.A., Rosario, A., Timko, M.A., Nealson, P.A., Kumagai, K.K., 2006. Hydroacoustic evaluation of spawning red hind (Epinephelus guttatus) aggregations along the coast of Puerto Rico in 2002 and 2003. In: Emerging technologies for reef fisheries research and management. Seattle, WA, NOAA, pp. 10-17. (NOAA Professional Paper NMFS, 5) 
Kennedy, J., Jónsson, S.P., Ólafsson, H.G. and Kasper, J.M., 2016. Observations of vertical movements and depth distribution of migrating female lumpfish (Cyclopterus lumpus) in Iceland from data storage tags and trawl surveys. ICES Journal of Marine Science: Journal du Conseil, 73(4), pp.1160-1169.

Kessel, S.T., Cooke, S.J., Heupel, M.R., Hussey, N.E., Simpfendorfer, C.A., Vagle, S., Fisk, A.T., 2014. A review of detection range testing in aquatic passive acoustic telemetry studies. Rev. Fish Biol. Fisher. 24, 199-218.

Killen, S.S., Brown, J.A., Gamperl, A., 2007. The effect of prey density on foraging mode selection in juvenile lumpfish: balancing food intake with the metabolic cost of foraging. $\mathrm{J}$ Anim. Ecol. 76, 814-825.

Leclercq, E., Davie, A., Migaud, H., 2014. Delousing efficiency of farmed ballan wrasse (Labrus bergylta) against Lepeophtheirus salmonis infecting Atlantic salmon (Salmo salar) post-smolts. Pest Manag. Sci. 70, 1274-1282.

Leclercq, E., Graham, P., Migaud, H., 2015. Development of a water-stable agar-based diet for the supplementary feeding of cleaner fish ballan wrasse (Labrus bergylta) deployed within commercial Atlantic salmon (Salmon salar) net-pens. Anim. Feed Sci. Technol. 208, 98-106.

Lein, I., Noble, C., Nergaard, S., Helland, S., 2014. Delousing of Atlantic salmon with two different sizes of farmed wrasse. In: Helland, S., Dahle, S.W., Hough, C., Borthen, J. (Eds.), 
Production of Ballan Wrasse (Labrus bergylta) Science and Practice. Belgium: Unijep, pp. $107-112$.

Lepper, P.A., Turner, V.L.G., Goodson, A.D., Black, K., 2004. Source levels and spectra emitted by three commercial aquaculture anti-predation devices. In: Proceedings of the Seventh European Conference on Underwater Acoustics, Seventh European Conference on Underwater Acoustics, ECUA 2004 Delft, The Netherlands, 5-8 July, 2004, pp. 1039-1044.

Martins, C.I., Galhardo, L., Noble, C., Damsgård, B., Spedicato, M.T., Zupa, W., Beauchaud, M., Kulczykowska, E., Massabuau, J.C., Carter, T., Planellas, S.R., 2012. Behavioural indicators of welfare in farmed fish. Fish Physiol. Biochem. 38, 17-41.

Mitamura, H., Thorstad, E.B., Uglem, I., Bjørn, P.A., Økland, F., Næsje, T.F., Dempster, T., Arai, N., 2012. Movements of lumpsucker females in a northern Norwegian fjord during the spawning season. Env. Biol. Fish. 93, 475-481.

Mulcahy, D.M., 2003. Surgical implantation of transmitters into fish. ILAR J. 44, 295-306.

Nielsen, A., 2011. Hydrographic survey, Loch Leven. Marine Harvest (Scotland) Ltd, Fort William, Scotland, $30 \mathrm{pp}$.

Norwegian directorate of fisheries. Aquaculture statistics booklets: key figures from the Norwegian aquaculture industry. Booklets. 2013. Available:

http://www.fiskeridir.no/English/Aquaculture/Statistics/Booklets 
Perry, R.W., Adams, N.S., Rondorf, D.W., 2001. Buoyancy compensation of juvenile Chinook salmon implanted with two different size dummy transmitters. Trans. Am. Fish. Soc. $130,46-52$.

Pollom, R.A., Rose, G.A., 2016. A global review of the spatial, taxonomic, and temporal scope of freshwater fisheries hydroacoustics research. Env. Rev. 24, 333-347.

Quignard, J.P., Pras, A., 1986. Labridae. In: Whitehead, P.J.P., Bauchot, M.L., Hureau, J.C., Nielsen, J., Tortonese, E. (Eds.), Fishes of the north-eastern Atlantic and the Mediterranean, vol 2. Paris: UNESCO, pp. 919-942.

Rillahan, C., Chambers, M.D., Howell, W.H., Iii, W.H.W., 2011. The behavior of cod (Gadus morhua) in an offshore aquaculture net pen. Aquac, 310, 361-368.

Rillahan, C., Chambers, M., Howell, W.H., Iii, W.H.W., 2009. A self-contained system for observing and quantifying the behavior of Atlantic cod, Gadus morhua, in an offshore aquaculture cage. Aquac, 293, 49-56.

Roscoe, D.W., Hinch, S.G., Cooke, S.J., Patterson, D.A., 2011. HydrogeomorphologyEcology Interactions in River Systems. Riv. Res. Appl. 22, 1085-1095.

Skiftesvik, A.B., Blom, G., Agnalt, A., Durif, C.M., Browman, H.I., Bjelland, R.M., Harkestad, L.S., Farestveit, E., Paulsen, O.I., Fauske, M., Havelin, T., Johnsen, K., Mortensen, S., 2014. Wrasse (Labridae) as cleaner fish in salmonid aquaculture-The Hardangerfjord as a case study. Mar. Biol. Res. 10, 289-300. 
Serrano, I., Larsson, S., Eriksson, L.O., 2009. Migration performance of wild and hatchery sea trout (Salmo trutta L.) smolts-Implications for compensatory hatchery programs. Fish. Res. 99, 210-215.

Treasurer, J.W. 2002. A review of potential pathogens of sea lice and the application of cleaner fish in biological control. Pest. Manag. Sci. 58, 546-558.

Treasurer J.W., 2013. SARF068 Use of Wrasse in Sea Lice Control. Scottish Aquaculture Research Forum. 30. ISBN: 978-1-907266-56-0

Turner, J.R., Warman, C.G., 1991. The mobile fauna of sublittoral cliffs. In: Myers, A.A., Little, C., Costello, M.J., Partridge, J.C. (Eds.), The Ecology of Lough Hyne. Dublin: Royal Irish Academy, pp. 127-138.

Tyack, P.L., 2008. Implications for marine mammals of large-scale changes in the marine acoustic environment. J. Mammal. 89, 549-558.

Villegas-Ríos, D., Alonso-Fernández, A., Domínguez-Petit, R., Saborido-Rey, F., 2013. Intraspecific variability in reproductive patterns in the temperate hermaphrodite fish, Labrus bergylta. Mar. Fresh. Res. 64, 1156-1168.

Wheeler, A., Du Heaume, V., 1969. The fishes of the British Isles and north-west Europe. $1^{\text {st }}$ ed. London: Macmillan and Co. 
Winter, J.D., 1996. Advances in underwater biotelemetry. In: Murphy, B.R., Willis, D.W. (Eds.). Fisheries Techniques. Bethesda: American Fisheries Society, pp. 555-590.

Wroblewski, J.S., Bailey, W.L., Howse, K.A., 1994. Observations of adult Atlantic cod (Gadus morhua) overwintering in nearshore waters of Trinity Bay, Newfoundland. Can. J. Fish. Aquat. Sci. 51, 142-150. 
Figure 1. Plan-view schematic of $24 \times 24 \mathrm{~m}$ square pens 7 (lumpfish) and 8 (ballan wrasse) in the study Cartesian coordinate system showing the positioning of the cleaner-fish shelter areas $(4 \times 4 \times 4 \mathrm{~m}$; grey squares $)$ and the hydrophone array deployed across two horizontal planes at $1 \mathrm{~m}$ and $20 \mathrm{~m}$ depth. $7 \mathrm{a}, 7 \mathrm{~b}, 8 \mathrm{a}, 8 \mathrm{~b}=$ wrasse hide $(1 \mathrm{~m} \varnothing, 2 \mathrm{~m}$ height; plastic fakekelp); $7 \mathrm{c}$ to $7 \mathrm{~h}=$ lumpfish hide (100 L smooth surface plastic barrels); HP = hydrophone.

Figure 2. Status of experimental (a) ballan wrasse and (b) lumpfish after deployment. Short black lines represent releases. Numbers in italic are the number of days each fish was deemed to exhibit normal behaviour after release (dark grey). All positions from suspected dead or moribund fish were discarded (light grey area). Black dotted lines highlight the experimental period (Days 83-151 inclusive).

Figure 3. (a) Plan-view positioning; (b) depth profile and (c) 3D positioning of an individual ballan wrasse (Tag 8,907 msec) during daytime and night time from day 117 (27 ${ }^{\text {th }}$ April 2015) 12 AM to day $119\left(29^{\text {th }}\right.$ April 2015) 12 AM.

Figure 4. (a) Plan-view positioning; (b) depth profile and (c) 3D positioning of an individual lumpfish (Tag 10,503 msec) during daytime and night time from day 117 (27 $7^{\text {th }}$ April 2015) 12 AM to day 119 (29 ${ }^{\text {th }}$ April 2015) 12 AM.

Figure 5. Average depth during daytime and night time of (a) individual ballan wrasse (B) and lumpfish $(\mathrm{L})$ over the study period (Mean \pm STDEV with $\mathrm{n}=22-69$ days $/$ specimen) and of the experimental (b) ballan wrasse and (c) lumpfish populations per day (Mean \pm SEM with $\mathrm{n}=5-9$ ballan wrasse / day and 4-9 lumpfish / day). 
Figure 6. Average minimum swimming speed during daytime and night time of (a) individual ballan wrasse (B) and lumpfish (L) over the study period (Mean \pm STDEV with $\mathrm{n}=22-69$ days / specimen) and of the experimental (b) ballan wrasse and (c) lumpfish population per day (Mean \pm SEM with $\mathrm{n}=5-9$ ballan wrasse /day and 4-9 lumpfish / day).

Figure 7. Average proportion of time spent each day at different pen locations by (a) the ballan wrasse population during daytime and (b) night time and by (c) the lumpfish population during daytime and (d) night time (Mean \pm SEM with $n=5-9$ ballan and 4-9 lumpfish / day). 


\section{Figure 1}

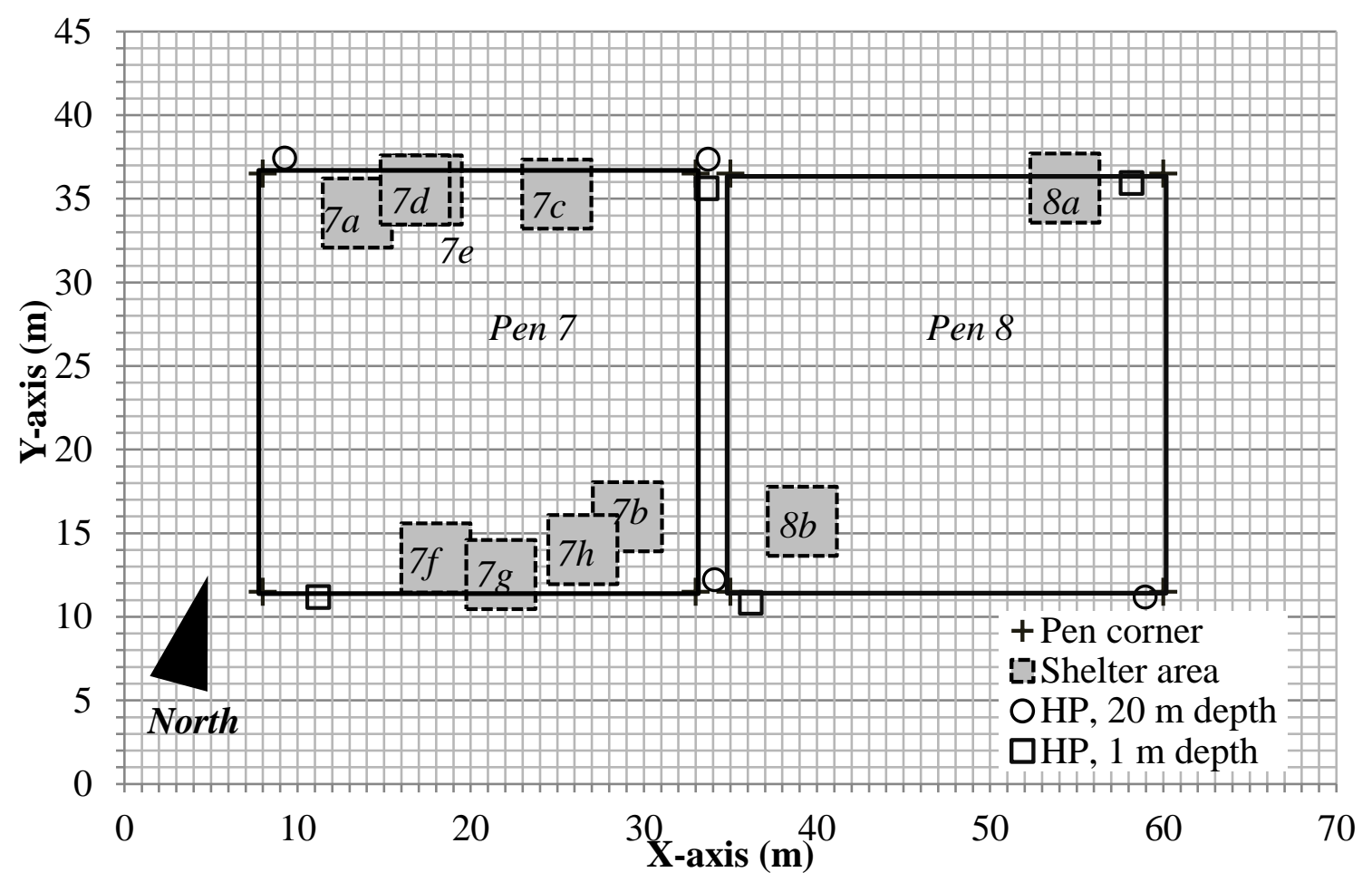

Figure 2

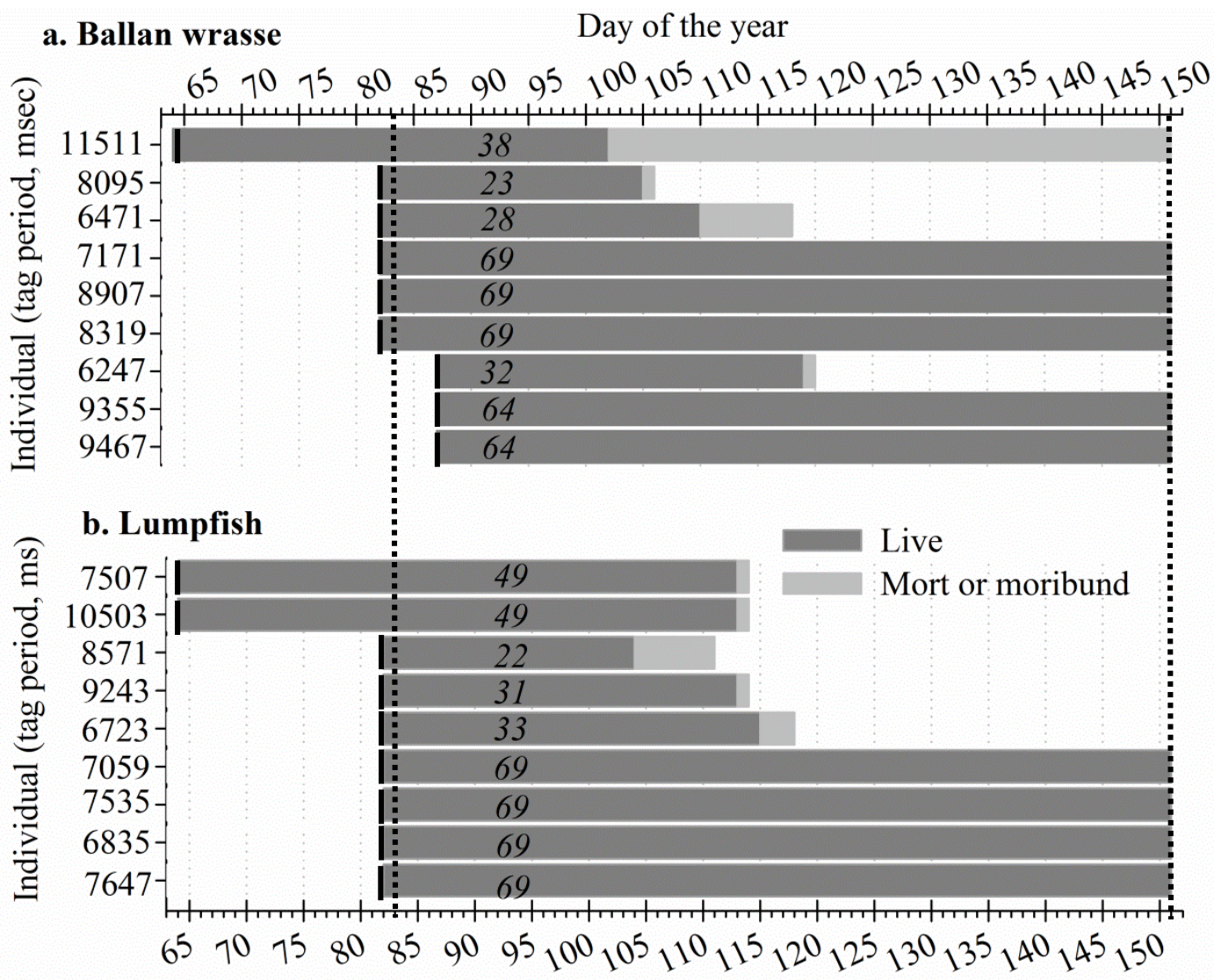

Day of the year 
Figure 3
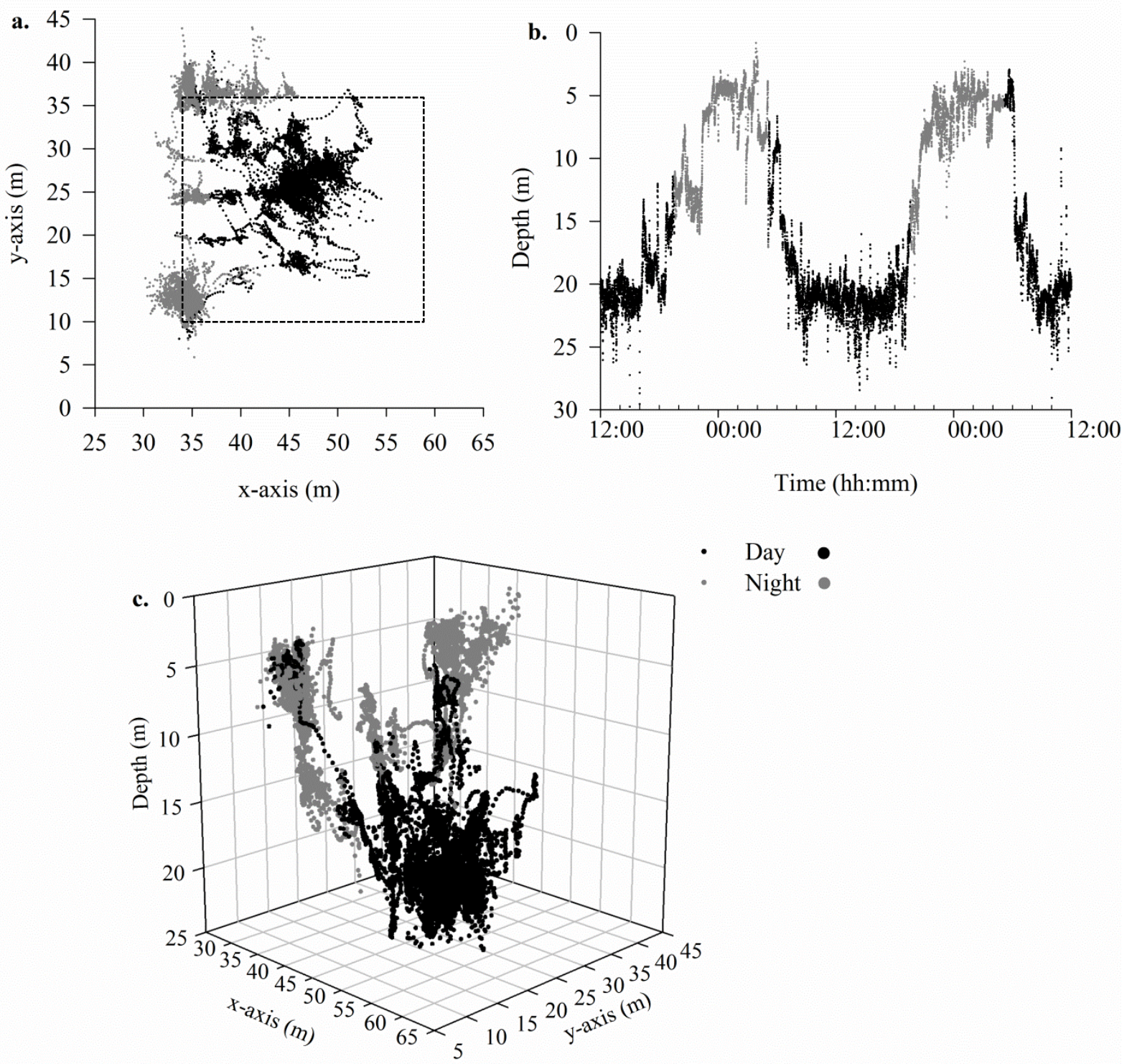
Figure 4
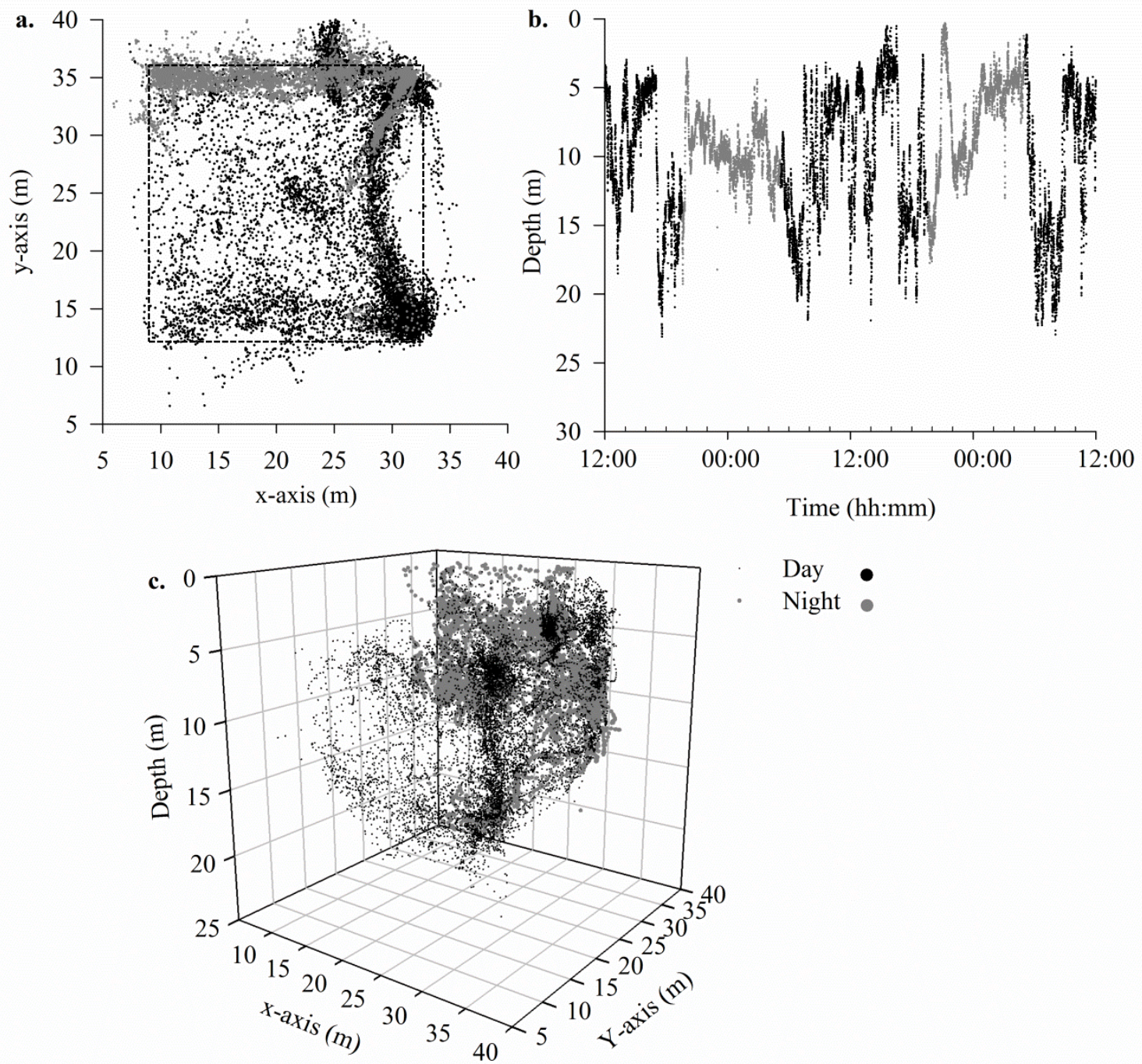
Figure 5
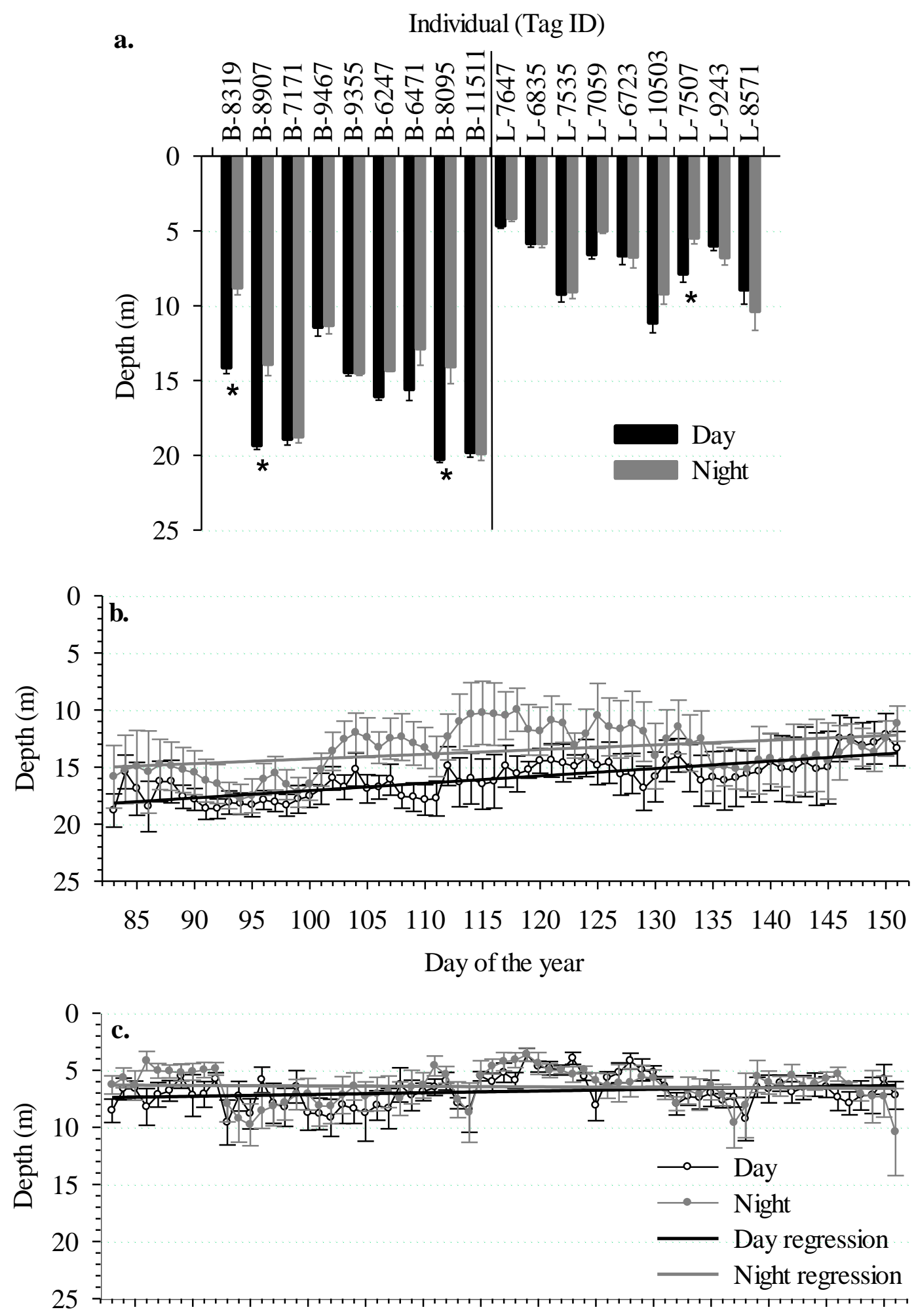

$\begin{array}{llllllllllllll}85 & 90 & 95 & 100 & 105 & 110 & 115 & 120 & 125 & 130 & 135 & 140 & 145 & 150\end{array}$

Day of the year 
Figure 6
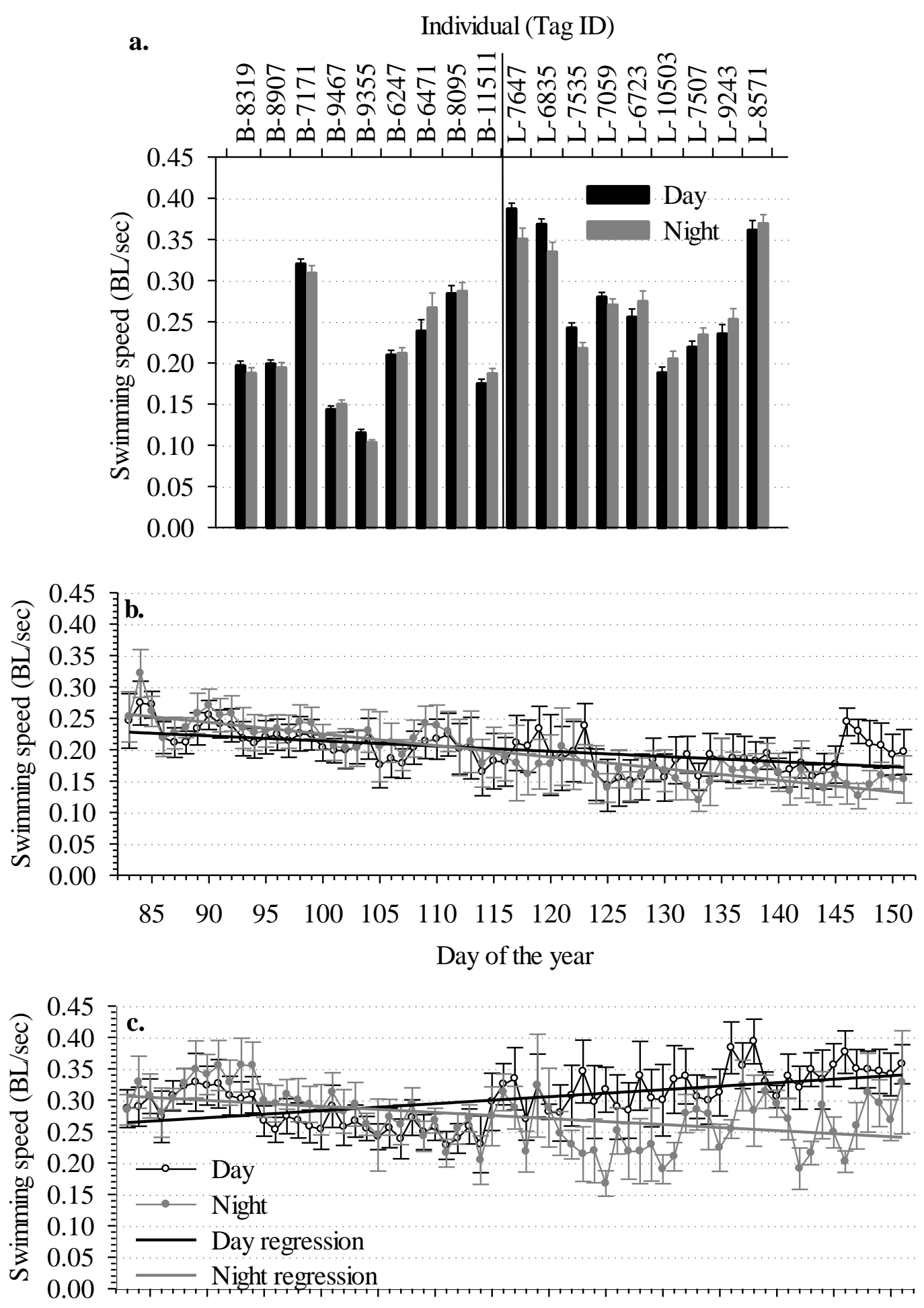

$\begin{array}{llllllllllllll}85 & 90 & 95 & 100 & 105 & 110 & 115 & 120 & 125 & 130 & 135 & 140 & 145 & 150\end{array}$

Day of the year 
Figure 7
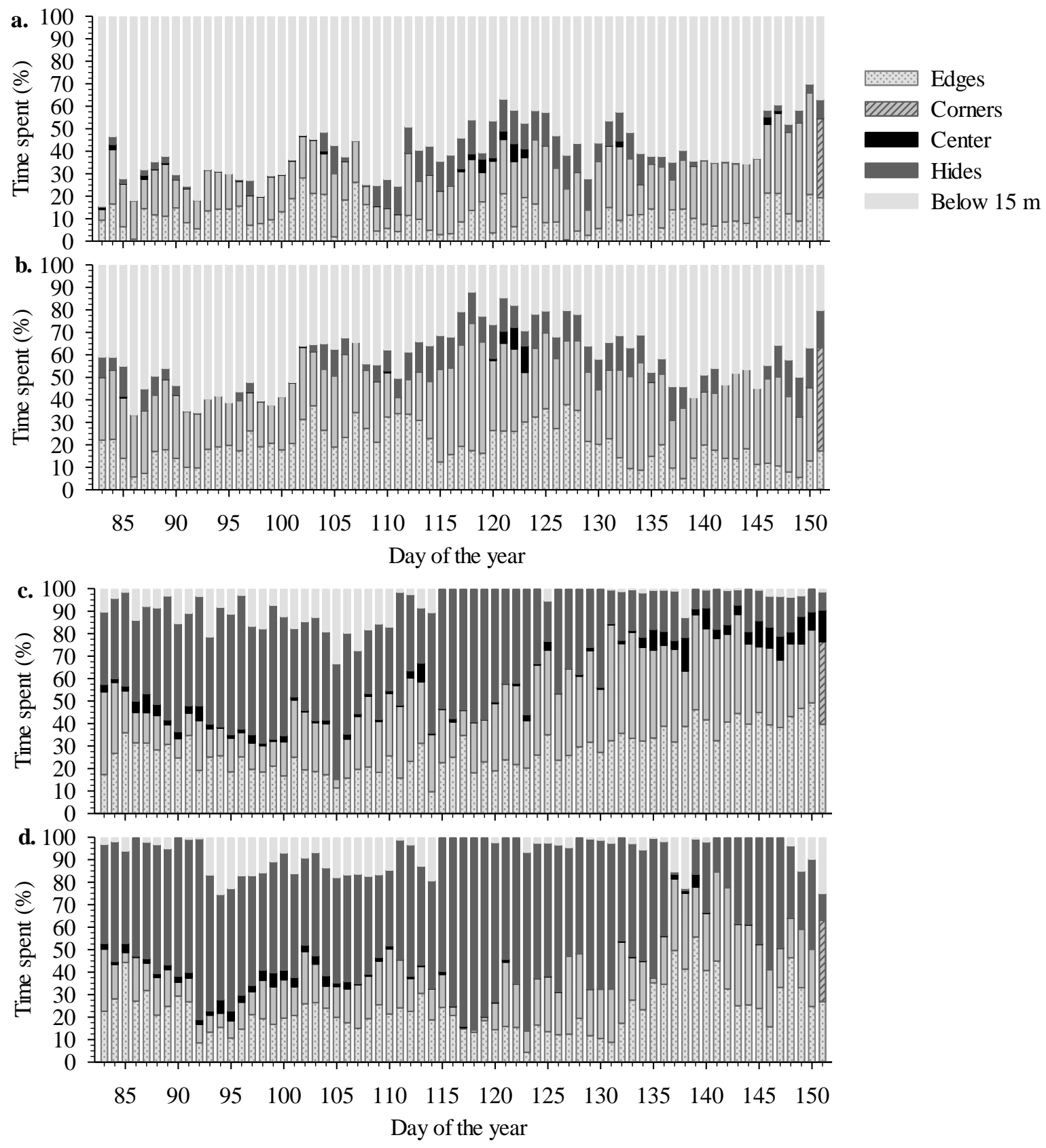